\title{
Feasibility of borehole reflection seismology for hard rock mineral exploration.
} Andrew Greenwood*, Milovan Urosevic and Roman Pevzner. Curtin University of Technology, Western Australia.

\section{Summary}

Complex geological models typical of hard rock mineral exploration in the Yilgarn Craton of Western Australia have been created. Through full waveform synthetic modeling, borehole reflection seismology has been tested in these environments with borehole geometries typical of hard rock exploration techniques. One such example is presented here. Synthetic testing has shown that borehole reflection seismic sections suffer from lack of aperture in the down-dip direction. Thus Large offsets and higher shot density is required on the down-dip side of the borehole to compensate for this. However at large offsets wavefield identification is complex and correct separation of wavefields for imaging is difficult. These limitations and acquisition specific geometries and processing are discussed here. Initial field studies conducted during a pilot study show potential for seismic imaging from angled boreholes.

\section{Introduction}

Recent 2D and a pilot 3D seismic reflection studies in the Yilgarn Craton of Western Australia have successfully produced high resolution images delineating nickel bearing rock units (Urosevic et al., 2007). These successes have led to a number of mining companies conducting larger scale 3D seismic surveys in the Kambalda and Agnew - Wiluna regions of the Yilgarn. Hard Rock (HR) environments are geological highly complex and produce many seismic paterns which are difficult to interpret (Urosevic et al., 2005). With this complexity arises many interpretation questions and a need to accurately calibrate seismic data by combining borehole and geological information. As such seismic "borehole ties" and targets are now being drilled. These should include the use of seismic velocity check-shot and Full Waveform Sonic (FWS) surveys to improve images and interpretation through; accurate depth to time conversions, improving migration velocities, determining wavelet phase shifts, identifying target and rock unit attributes.

Due to the typical angled borehole and steeply dipping target geometries found in HR exploration, check shot surveys offer the possibility to seismically image around the hole when combined with walk-away and offset shot locations. Inherently borehole seismic imaging is of higher resolution than surface seismic due to the receivers being within the host formations, preserving frequency content from the destructive scattering effects of irregular thick overburdens (regolith). Also reflection events can be directly correlated to core logs or wire-line data. In particular borehole reflection seismology can offer an increased understanding of the origin of the events and structural complexity around the borehole.

To test the viability of borehole reflection seismology in HR environments, we modeled a complex geological environment found in the Yilgarn Craton. The objectives of the study were to; investigate the applicability of borehole reflection seismology, determine major limitations, and develop new field surveying techniques and approaches to data processing.

\section{Modeling}

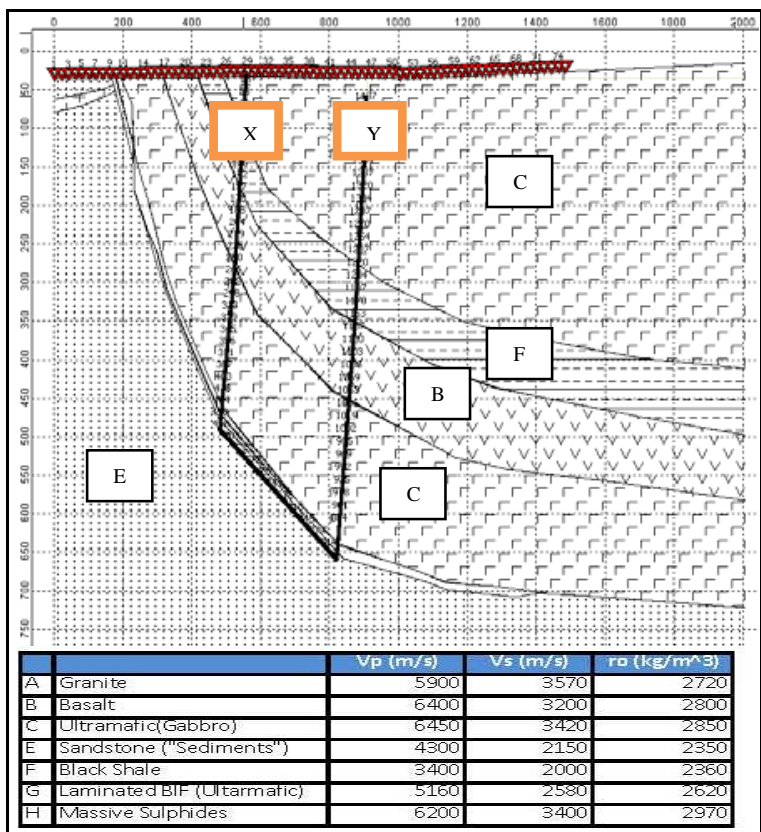

Figure 1:Geologic model for nickel reserve in the southern Yilgarn. Nickel sulphides lie on the interface between the sedimentry and ultramafic boundaries $\mathrm{E}$ and $\mathrm{C}$. Respective $\mathrm{Vp}, \mathrm{Vs}$ and densities used are shown in the table. Two boreholes $\mathrm{X}$ and $\mathrm{Y}$ are shown with reciever stations at $5 \mathrm{~m}$ intervals. 75 shot stations at $20 \mathrm{~m}$ separations are shown as Red triangles across the surface.

The initial cross section (model) was taken from a nickel deposit in the south of the Yilgarn Craton. This is shown in Figure 1. The nickel deposit lies on an upturned interface between sediments' and ultramafics. Two boreholes $\mathrm{X}$ and $\mathrm{Y}$ approximately $400 \mathrm{~m}$ apart were populated with receiver 


\section{Feasibility of borehole reflection seismology for hard rock mineral exploration}

stations every $5 \mathrm{~m}$. A total of 75 shot stations were located along the surface at $20 \mathrm{~m}$ stations crossing borehole $\mathrm{X}$ at station 29 and borehole $\mathrm{Y}$ at station 47 . Seismic velocities and densities were taken from Salisbury et al., 2000, and Dobrin and Savit, 1988.

Synthetic modeling was conducted using TesseralCS-2D full waveform modeling package. Acoustic modeling was initially used to understand energy propagation in this complex geological environment. The effects of conversion were ignored at this stage of modeling. Other complex earth models have been created with elastic wave equation. However they are not shown here as they produce overly complex responses.

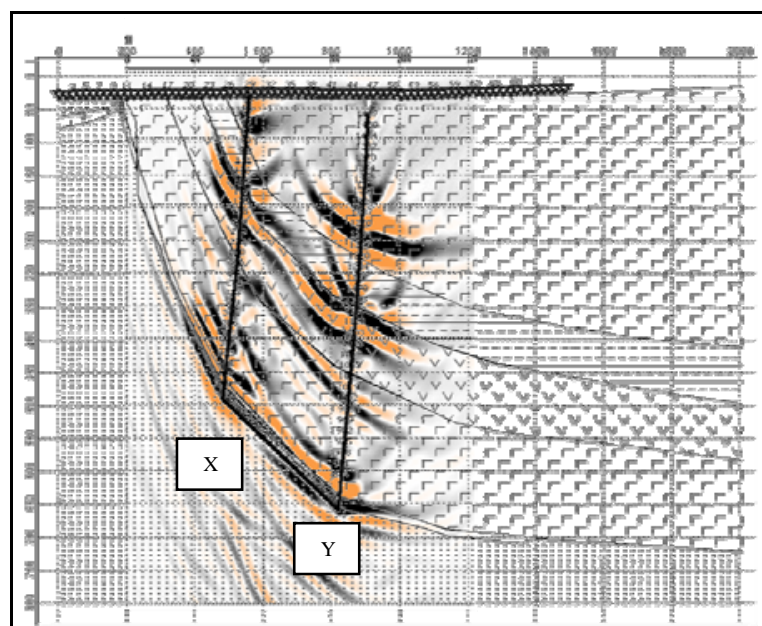

Figure 2: Stacked migrated section constructed from from the synthetic results from boreholes $\mathrm{X}$ and $\mathrm{Y}$. A constant velocity model of $6.2 \mathrm{~km} / \mathrm{s}$ was used for both boreholes. Reflection events corelate well with geological interfaces in borehole $\mathrm{X}$ and less well in borehole $\mathrm{Y}$.

Spatial sampling of the recorded wavefield was of particular importance for this study. Processing with $5 \mathrm{~m}$ and $10 \mathrm{~m}$ station spacing in the borehole were trialed. Each borehole was processed separately. At $5 \mathrm{~m}$ receiver stations data density was sufficient to use an F-K polygon reject filter to separate the up-going and down-going wave fields. Kirchhoff migration was then used to migrate synthetic shot records prior to CDP stacking. Different offsets were analyzed and it was determined that reflection energy was minimal up-dip. The highly dipping nature of the lithologies and subsequent geometry of sources and receivers here, imply that reflection energy is refracted and guided within layers. This is particularly evident in the larger up-dip shot locations (geologically up dip from the collar position) where the reflector planes are obtuse to the shot propagation direction. Such shot records were removed before CDP stacking. Different velocity models were also trialed. Finally migrated shot records were stacked together to produce a final migrated image.

Figure 2 shows the final migrated section constructed from both boreholes $\mathrm{X}$ and $\mathrm{Y}$. A constant velocity model of $6.2 \mathrm{~km} / \mathrm{s}$ was used for processing. This velocity model works well for borehole $\mathrm{X}$ where reflection energy is coinciding with unit contacts. However the corresponding reflections do not line up as well on borehole Y.

If we inspect the image around each borehole separately it is evident that imaging aperture is less on the down-dip side of the borehole.

\section{Field trial}

These promising modeling results inspired field studies. An example of such work is illustrated in Figure 3. Here Zerooffset Vertical Seismic Profiling (ZVSP) data has had the down-going wave field removed and converted to two way travel time (TWTT or +TT). It is presented alongside wireline data specifically; resistivity (RLLS), FWS P and Swave velocities, density and the corresponding computed reflectivity and acoustic impedance. This data was collected as part of a uranium exploration, surface seismic pilot study. A 3-component borehole geophone was used at $10 \mathrm{~m}$ station spacing's between $50 \mathrm{~m}$ to $340 \mathrm{~m}$ depth. The basic geology is a sequence of muscovite and chloritic schist's unconformably overlie carbonates and a gneiss basement. This is illustrated in Figure 4.

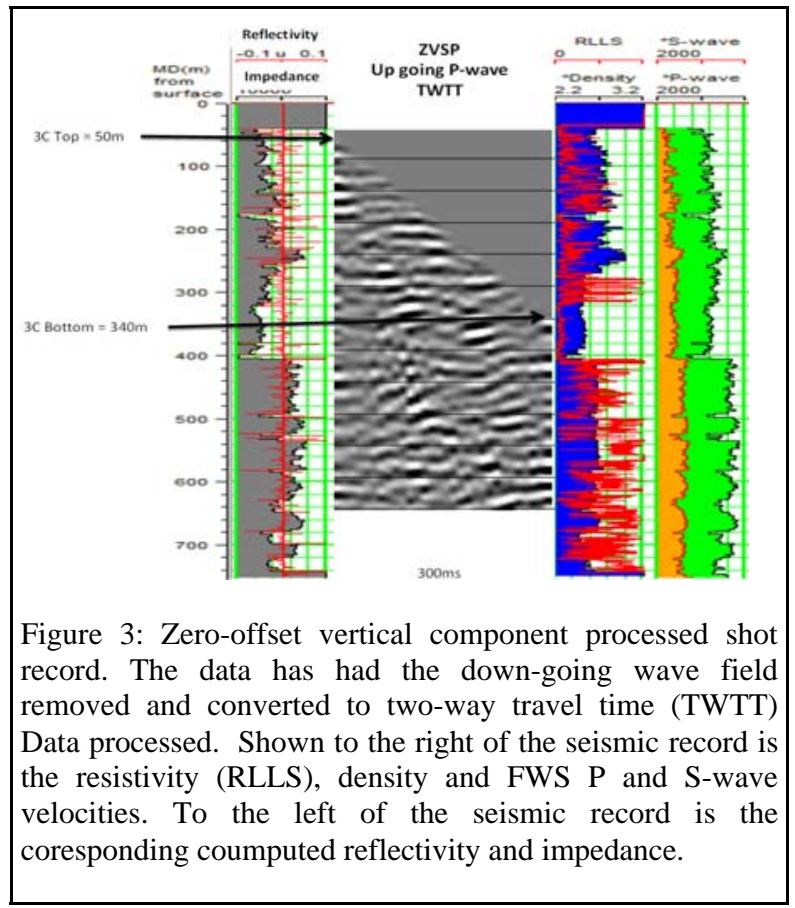




\section{Feasibility of borehole reflection seismology for hard rock mineral exploration}

The ZVSP data correlates well to the wire-line logs with multiple reflections events particularly strong at $270 \mathrm{~m}$ and $400 \mathrm{~m}$. Due to field logistic issues only these 30 stations could be collected and a migrated image has not been attempted.

The geological cross-section corresponding to the borehole data in Figure 3 is shown in Figure 4. Also shown in Figure 4 is the impedance / reflectivity log of Figure 3 and a pilot 2D surface seismic section. This section was collected using 30 geophones at $10 \mathrm{~m}$ stations. 61 shot points were used shooting at and between every geophone station using a Force 9 weight drop source. The section was processed using a velocity model derived from the ZVSP. Correlations between the reflection horizons in the $2 \mathrm{D}$ and ZVSP can be made.

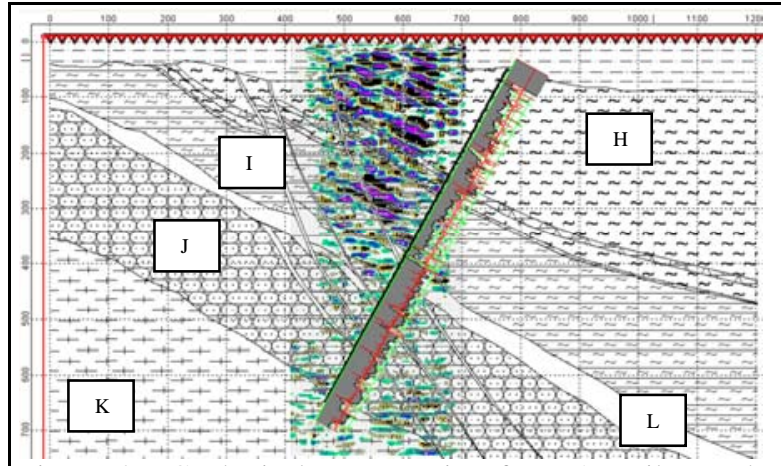

Figure 4: Geological cross-section for a 2D pilot study. Lithological units are $\mathrm{H}$-muscovite schist, I-chloritic schist, J-carbonates, K-gneiss. A shear zone L separates units I and J. High resolution 2D data collected aong profile and acoustic impedance and reflectivity logsare shown overlying the section

\section{Conclusions}

Synthetic testing has shown that it is possible to produce reflection seismic sections in hard rocks from angled boreholes.

Migrated images suffer from lack of aperture in the downdip direction. Large offsets and higher shot density is required on the down-dip side of the borehole to compensate this. However at large offsets wavefield identification is difficult and correct separation of wavefields for imaging is difficult.

Up-dip and down-dip shots need to be carefully examined at each stage of processing to determine the limits at which reflection energy is no longer being added to the stack. In the up-dip direction this is reached quickly (approximately the lateral extent of the receivers in the up-dip direction). In the down dip direction it is harder to create a "rule of thumb" and modeling of each individual geologic setting is required before acquisition.

Due to the steep dips of lithological units the velocity field varies laterally and it is necessary to determine a velocity model for each hole separately.

Initial Field studies indicate that acoustic impedance contrasts are sufficient to create strong reflection events in a complex geologic environment schist carbonates. This is encouraging of borehole seismic imaging in hard rocks.

Borehole depths in HR exploration are typically between $200-700 \mathrm{~m}$. As such it is necessary to spatially oversample in the hole to accurately use any $2 \mathrm{D}$ filtering methods for wave field separation.

\section{Acknowledgments}

We are grateful to the Centre of Excellence for High Definition Geophysics at Curtin University of Technology for the financial support and implementation of research into hard rock borehole seismology. 


\section{EDITED REFERENCES}

Note: This reference list is a copy-edited version of the reference list submitted by the author. Reference lists for the 2010 SEG Technical Program Expanded Abstracts have been copy edited so that references provided with the online metadata for each paper will achieve a high degree of linking to cited sources that appear on the Web.

\section{REFERENCES}

Dobrin, M. B., and C. H. Savit, 1988, Introduction to Geophysical Prospecting: McGraw-Hill Book Co.

Salisbury, M. H., B. Milkereit, G. Ascough, R. Adair, L. Matthews, D. R. Schmitt, J. Mwenifumbo, D. W. Eaton, and J. Wu, 2000, Physical properties and seismic imaging of massive sulfides: Geophysics, 65, 1882-1889, doi:10.1190/1.1444872.

Urosevic, M., and A. Kepic, 2007, Seismic exploration of ore deposits in Western Australia:Exploration '07

Urosevic, M., and E. Stolz, 2005, Seismic exploration for gold in a hard rock environment - Yilgarn Craton, Western Australia:67th Meeting, EAGE. 